\title{
NEW THICK FILM SENSORS
}

\author{
S. LEPPÄVUORI \\ Microelectronics Laboratory, Department of Electrical Engineering, University of Oulu, \\ Box 191, SF-90101 Oulu 10, Finland
}

(Received May 5, 1979)

\begin{abstract}
Various thick film sensors which are under development in the Microelectronics laboratory of the University of Oulu are described. More details are included on the capacitive thick film temperature sensor which is in the application stage. Other thick film sensors at present in the material development stage are the resistive humidity sensor, the gas sensor and the ion selective sensor.
\end{abstract}

\section{INTRODUCTION}

Sensors are becoming more and more important in electronic equipment due to the automation explosion and the increase in the capability of modern digital circuits to perform control operations. Thick film sensors have not been in large scale use to date but in the near future they will have to be able to satisfy a larger demand for sensors. We have, therefore, been using ceramic materials with many different properties to develop new types of thick film sensors.

\section{A THICK FILM CAPACITIVE TEMPERATURE SENSOR}

\subsection{General}

Ferroelectric materials above their Curie temperature have a dielectric constant which is strongly inversely proportional to temperature, which means that the reactance of a capacitor made with such a material is proportional to temperature. When this kind of capacitor is used as a temperature sensor, calibration and instrumentation are greatly simplified. Depending upon the temperature range required, the Curie temperature has to be adjusted by varying the composition of the ferroelectric material. By using different proportions of barium titanate and strontium titanate the Curie temperature may be shifted from about $-240{ }^{\circ} \mathrm{C}$ to $+120{ }^{\circ} \mathrm{C}$, the shift being approximately proportional to the barium titanate concentration over the entire range. The sensors can then be manufactured using thick film techniques. ${ }^{1,2}$

\subsection{Preparation of Sensor Paste}

A lead-borosilicate glass is used for the glass frit. The linear thermal expansion coefficient (TCE) can be shifted from $4.5 \times 10^{-6} /{ }^{\circ} \mathrm{C}$ to $9.5 \times 10^{-6} /{ }^{\circ} \mathrm{C}$ by varing the composition of the glass ( $\mathrm{PbO} 60 \ldots 80 \%, \mathrm{SiO}_{2} 15 \ldots 5 \%, \mathrm{~B}_{2} \mathrm{O}_{3} 10 \ldots 25 \%$ ). It is therefore possible to adjust the TCE of the glass so that stresses between the active ceramic powder

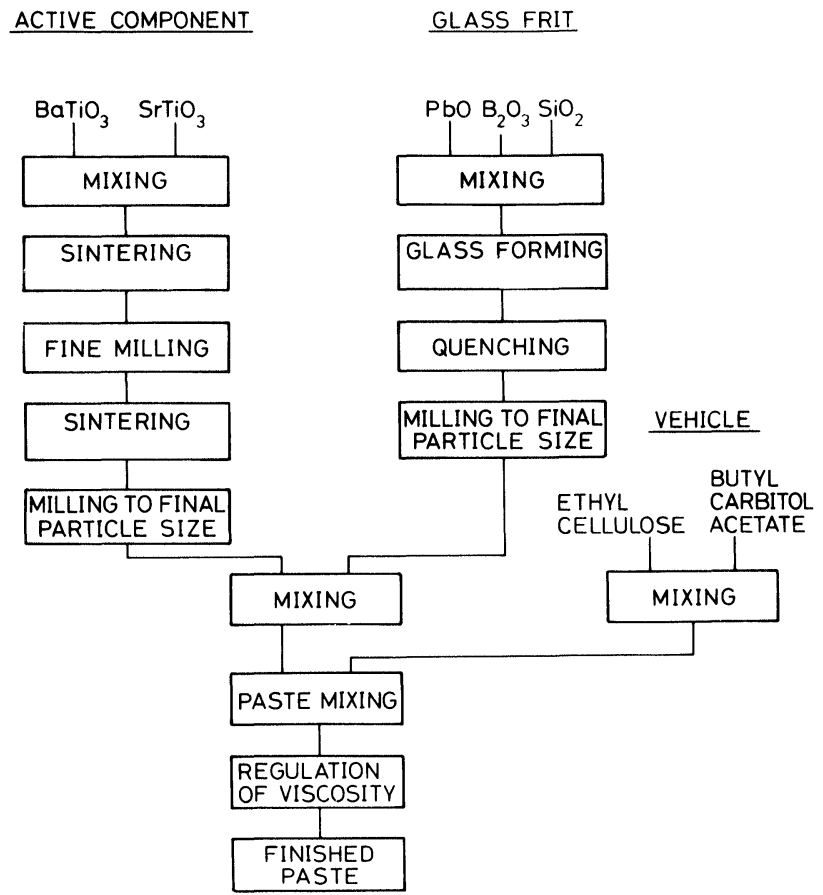

FIGURE 1 Preparation of sensor paste. 
$\left(\mathrm{TCE}=10 \times 10^{-6} /{ }^{\circ} \mathrm{C}\right)$ and the alumina substrate $\left(\mathrm{TCE}=6.5 \times 10^{-6} /{ }^{\circ} \mathrm{C}\right)$ are minimized.

The barium titanate and strontium titanate are commercial grade powders. Figure 1 summarises the processes involved in the paste preparation.

\subsection{Influence of the Glass Frit}

Standard thick film overlay capacitors and ceramic disk capacitors were used for the examination of the influence of the glass frit. Figure 2 shows the reciprocal dielectric constants normalized to a temperature of $120^{\circ} \mathrm{C}$ as a function of temperature for $50\left(\mathrm{BaTiO}_{3}\right)-50\left(\mathrm{SrTiO}_{3}\right)$ disk capacitors with a glass frit content of $0 \%$ (Curve 3) and 6 vol. \% (curve 2). Curve 1 refers to a sample made by thick film techniques. The most important effect demonstrated is the reduction in the temperature sensitivity of curves 1 and 2 compared with the ceramic in curve 3 . Also, it can be seen that curves 2 and 3 have generally a slightly reduced linearity compared with curve 3 and in particular, that the thick film material cannot be taken close to the Curie temperature of the ceramic $\left(-60{ }^{\circ} \mathrm{C}\right)$ without serious non-linearity occurring. Thus, it is necessary for good linearity to restrict the operating range of the device to temperatures above $\left(T_{0}+70^{\circ} \mathrm{C}\right)$ i.e. in the case of $(\mathrm{Ba}, \mathrm{Sr}) \mathrm{TiO}_{3}$ sensors, the minimum working temperature is between $-180^{\circ} \mathrm{C}$ and $+170^{\circ} \mathrm{C}$.

The effects of the glass component as a function of glass content show that for the best temperature

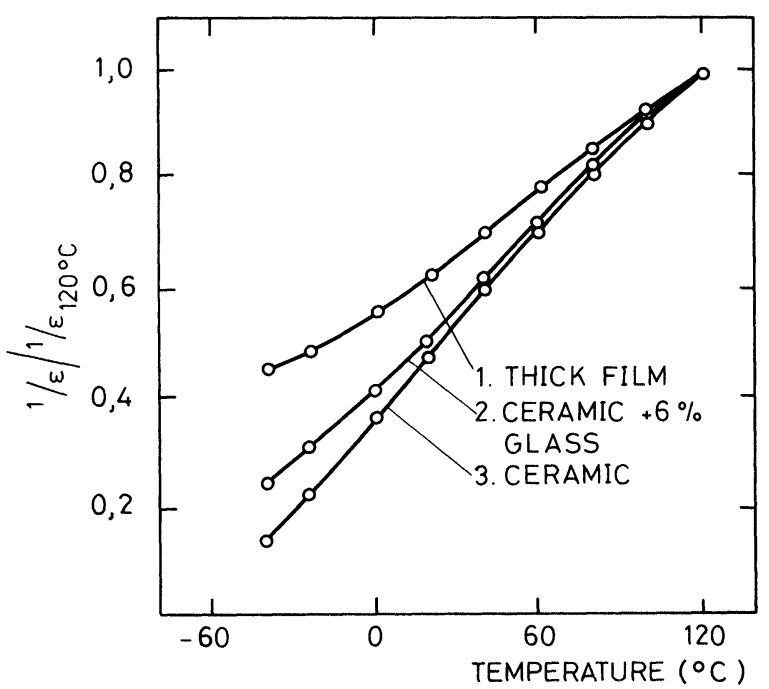

FIGURE 2 The reciprocal dielectric constant normalized to $120^{\circ} \mathrm{C}$ as a function of temperature. performance a glass frit content of the paste of between $6 \mathrm{vol}$. \% and $12 \mathrm{vol} . \%$ is probably optimum.

\subsection{Properties of the Sensor}

A sensor designed for the temperature range $0{ }^{\circ} \mathrm{C}$ to $100{ }^{\circ} \mathrm{C}$ was selected for the tests to evaluate the properties of the device. The glass content for the paste was 6 vol. \% and the active component $50\left(\mathrm{BaTiO}_{3}\right)-50\left(\mathrm{SrTiO}_{3}\right)$, the Curie temperature of which is about $-60^{\circ} \mathrm{C}$. This gives a sensor with high sensitivity and good linearity.

The sensors were manufactured in two different designs. Construction 1 is encapsulated in a protective coating, ESL 240-SB, which has been double printed. In Construction 2, where the top electrode covers nearly all of the dielectric, encapsulation is achieved by solder dipping the complete sensor to ensure that the electrode is non-porous. The uncovered part of the dielectric is coated with an epoxy.

The temperature response of the sensor was measured in a standard environmental chamber at a frequency of $1 \mathrm{kHz}$ (Figure 3 and Table I).

The following tests were performed to examine the stability of the sensors:

- Dry heat (IEC $68-2-2$ ), at $+100^{\circ} \mathrm{C}$ for 96 hours.

- Damp heat, steady state (IEC $68-2-3$ ), at $+40{ }^{\circ} \mathrm{C}$ and $93 \%$ RH for 96 hours.

- Change of temperature (IEC 68-2-14), where each

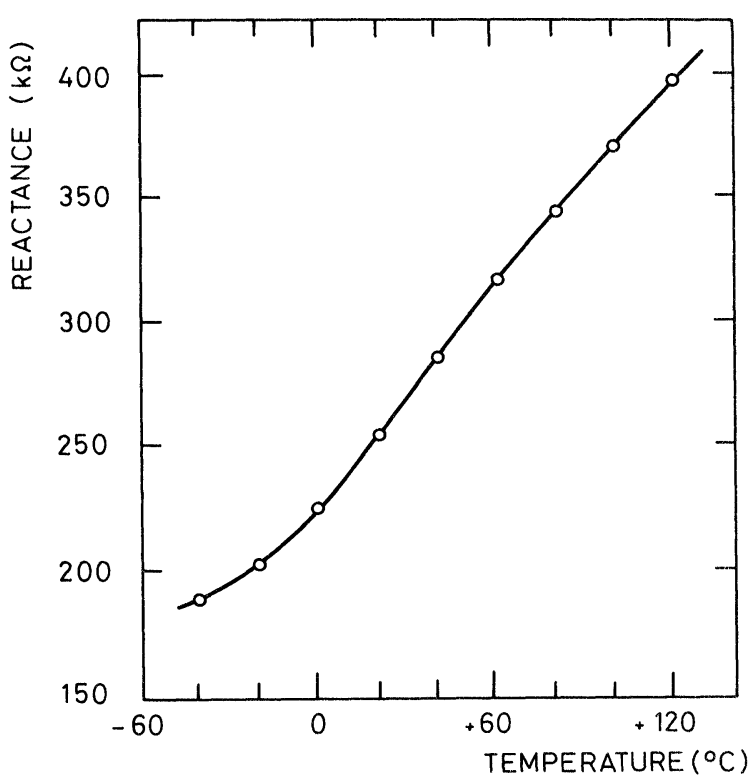

FIGURE 3 The temperature response of a thick film sensor for use over the range $0{ }^{\circ} \mathrm{C}$ to $+100^{\circ} \mathrm{C}$. 
TABLE I

Properties of the capacitive temperature sensor

\begin{tabular}{lll}
\hline Construction & 1 & 2 \\
\hline Protective coating & ESL $240-\mathrm{SB}$ & Solder $(2 \% \mathrm{Ag})$ \\
Change in reactance $\left(0^{\circ} \mathrm{C}\right.$ to $\left.+100^{\circ} \mathrm{C}\right)$ & $65 \%$ & $65 \%$ \\
Non linearity $\left(0^{\circ} \mathrm{C}\right.$ to $\left.+100^{\circ} \mathrm{C}\right)$ & $\pm 1.5 \%$ & $\pm 1.5 \%$ \\
Instability (max. changes in tests) & $-0.4 \ldots+1.1 \%$ & $-0.06 \% \ldots 1.8 \%$ \\
Thermal time constant $\left(10 \mathrm{~mm}^{2}\right.$ capacitor) & $19 \mathrm{~s}$ & $14.5 \mathrm{~s}$ \\
Capacitance per unit area $\left(1 \mathrm{kHz},+23^{\circ} \mathrm{C}\right)$ & $65 \mathrm{pF} / \mathrm{mm}^{2}$ & $65 \mathrm{pF} / \mathrm{mm}^{2}$ \\
Dissipation factor $\left(1 \mathrm{kHz},+23^{\circ} \mathrm{C}\right)$ & $0.6 \%$ & $0.6 \%$ \\
\hline
\end{tabular}

cycle lasted 10 hours of which 4 hours was at $0{ }^{\circ} \mathrm{C}$ and 4 hours at $+100^{\circ} \mathrm{C}$. The number of cycles was 5 and rate of temperature change $1.65^{\circ} \mathrm{C} / \mathrm{min}$. Table I summarizes the properties of the sensors.

\subsection{Applications}

This new type of sensor, which has been manufactured using standard thick film techniques, can be used
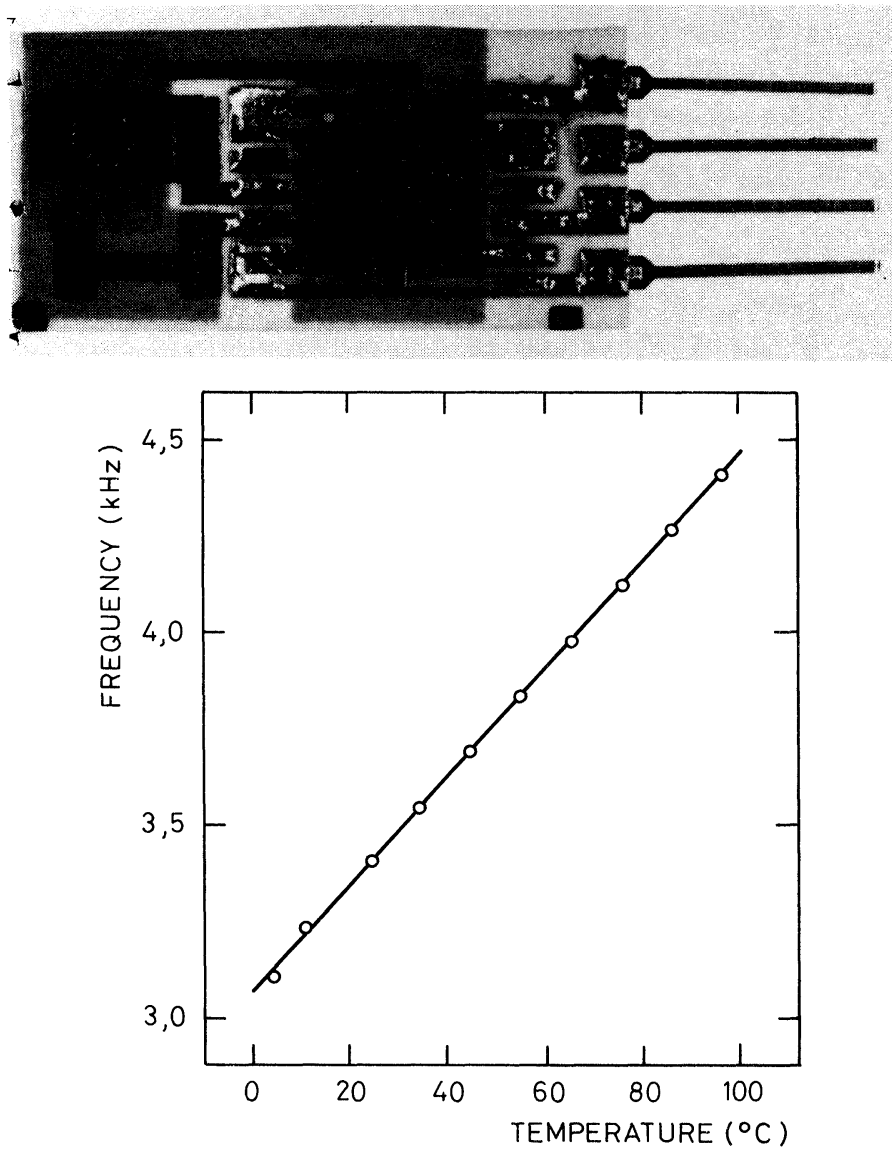

FIGURE 4. A CMOS oscillator using a thick film capacitor sensor and its output frequency as a function of temperature. either as a discrete sensor or alternatively, integrated with an oscillator to make a hybrid transducer. The capacitance value of the sensor can be varied up to many tens of nano-farads using multilayer techniques. Figure 4 shows a CMOS-oscillator using a thick film capacitor sensor and its output frequency as a function of temperature.

\section{THE DEVELOPMENT OF A THICK FILM HUMIDITY SENSOR}

\subsection{General}

The measurement of humidity is a very common problem which has not yet been generally solved. The development of a suitable sensor material has progressed from electrolytes to organic polymers and metal oxides. The first humidity sensor ${ }^{3}$ based on a metal oxide was the aluminium oxide sensor which is a capacitor formed by anodizing aluminium with a porous oxide layer and then coating the oxide with a metal layer. Water vapour penetrates the metal layer and is absorbed by the porous oxide layer changing the conductivity and thus the electrical impedance of the capacitor. At the present time humidity sensors using both ceramic and thick film techniques have been reported to be under development but it seems that there is still much research work to be done in this field. ${ }^{3}$

\subsection{Experiments}

Thick film humidity sensors can in principle, be based on either a change in conductivity or a change in permittivity. For the examination of the possible use of thick film capacitors as humidity sensors, some low and high permittivity dielectrics have been prepared and tested using normal thick film overlay capacitors. A common feature of all the capacitors was that they were only slightly humidity sensitive up to a relative humidity of $50 \%$ to $60 \%$ but after this 
their capacitances increased rapidly and became unstable. The measured change in the capacitance is, in fact, caused by a change in the surface conductivity of the pores. Since this is always an influencing factor it seems that the resistive sensor could be more profitable in thick film applications.

The structures of both the resistive ceramic and thick film humidity sensors are shown in Figure 5. In order that the water vapour will be absorbed quickly enough, the structure of the sensor has to be porous. With ceramic sensors this can be achieved by
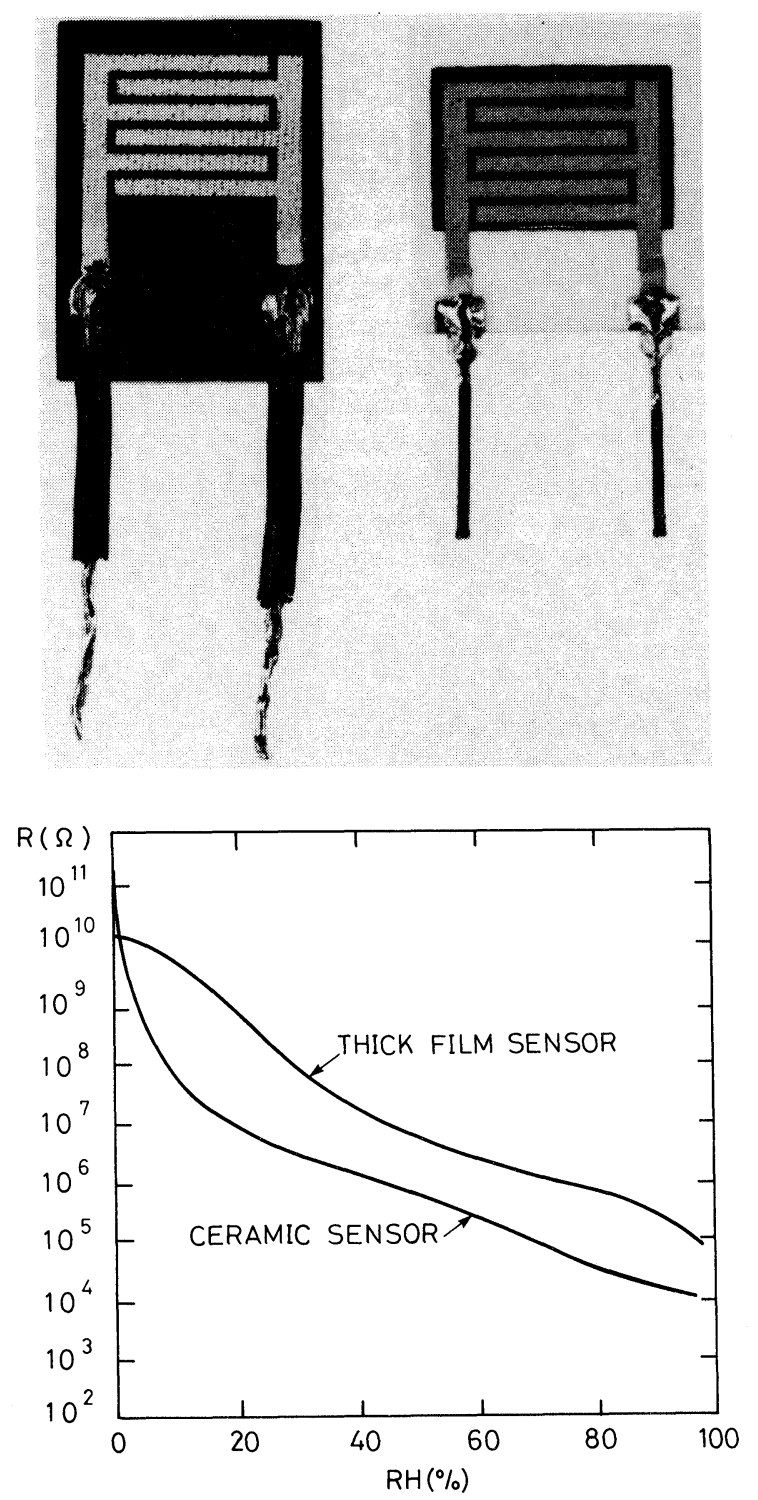

FIGURE 5. The ceramic and thick film humidity sensor and the relative humidity dependence of their resistance. using a suitable sintering profile. With thick film sensors the necessary glass frit reduces the porosity and humidity properties. This means that the correct choice of the amount of glass frit and the firing temperature are essential in order to achieve a good sensitivity and response time. The electrodes for both ceramic and thick film sensors were printed using a reactively-bonded gold paste. Figure 5 shows the relative humidity dependence of the resistance of both a ceramic and a thick film sensor made with the same ceramic material. The change of resistance of both sensors is large but from the point of view of most practical applications, it would be more desirable to have both a smaller resistance change and a smaller value of resistance in order to improve the basic stability. Measurements of surface and bulk resistivity show that the porosity of the ceramic material has been sufficiently large and also that the main influencing effect comes from the surface resistivity of the ceramic particles. Since the sensor material is still under development the properties of the sensors have not yet been fully characterized.

\section{OTHER SENSORS}

\subsection{Gas Sensors}

The resistivity of many ceramic materials is sensitive to gas as well as to humidity. A structure similar to the thick film humidity sensor can be used to measure gas content and experiments have shown that good sensitivity may be obtained with many gases e.g. carbon monoxide. This kind of thick film sensor would be extremely useful in many kinds of portable alarm and control systems.

\subsection{An Ion Sensitive Sensor}

It is also possible to make ion sensitive sensors with thick film techniques using a suitable ion-selective glass membrane. ${ }^{4}$ In order to produce a sensor, an ion-selective glass must be developed together with compatible electrode layers. Preliminary research work to develope a $\mathrm{pH}$-sensor has already been started in the laboratory.

\section{CONCLUSION}

This paper has described some current research work on thick film sensors. Such sensors have many future applications but need much more materials and development work. There is also a demand for novel 
sensor ideas. It is, therefore, important that this work be undertaken by more university research laboratories.

\section{ACKNOWLEDGEMENTS}

The author wishes to thank Mr. Kaarlo Heikkinen for his help with the experimental work and technical discussions and also Dr. A. E. Hill from the University of Salford, Salford, UK, for his help in writing this paper. The Finnish Ministry of Trade and Industry and the Tauno Tönning Foundation have supported this work financially.

\section{REFERENCES}

1. S. Leppävuori, and $P$. Niemelä, $A$ thick film capacitive temperature sensor, Proc. ECC, 47 (1978).

2. S. Leppävuori, T. Hannula, and A. Uusimäki, A thick film capacitive temperature sensor using barium strontium titanate glass formulations, Electrocom. Sci and Tech., 6 (1979).

3. T. Nitta, and Z. Tereda, Ceramic humidity sensitive resistor device, National technical report, Vol. 22 No. G (Dec. 1976).

4. M. Donald, A. Martin, and S. Sinclair, Fabrication of implantable $\mathrm{pH}$ electrodes utilizing thin and thick film techniques, Proc. ISHM, 166 (Oct. 1976). 

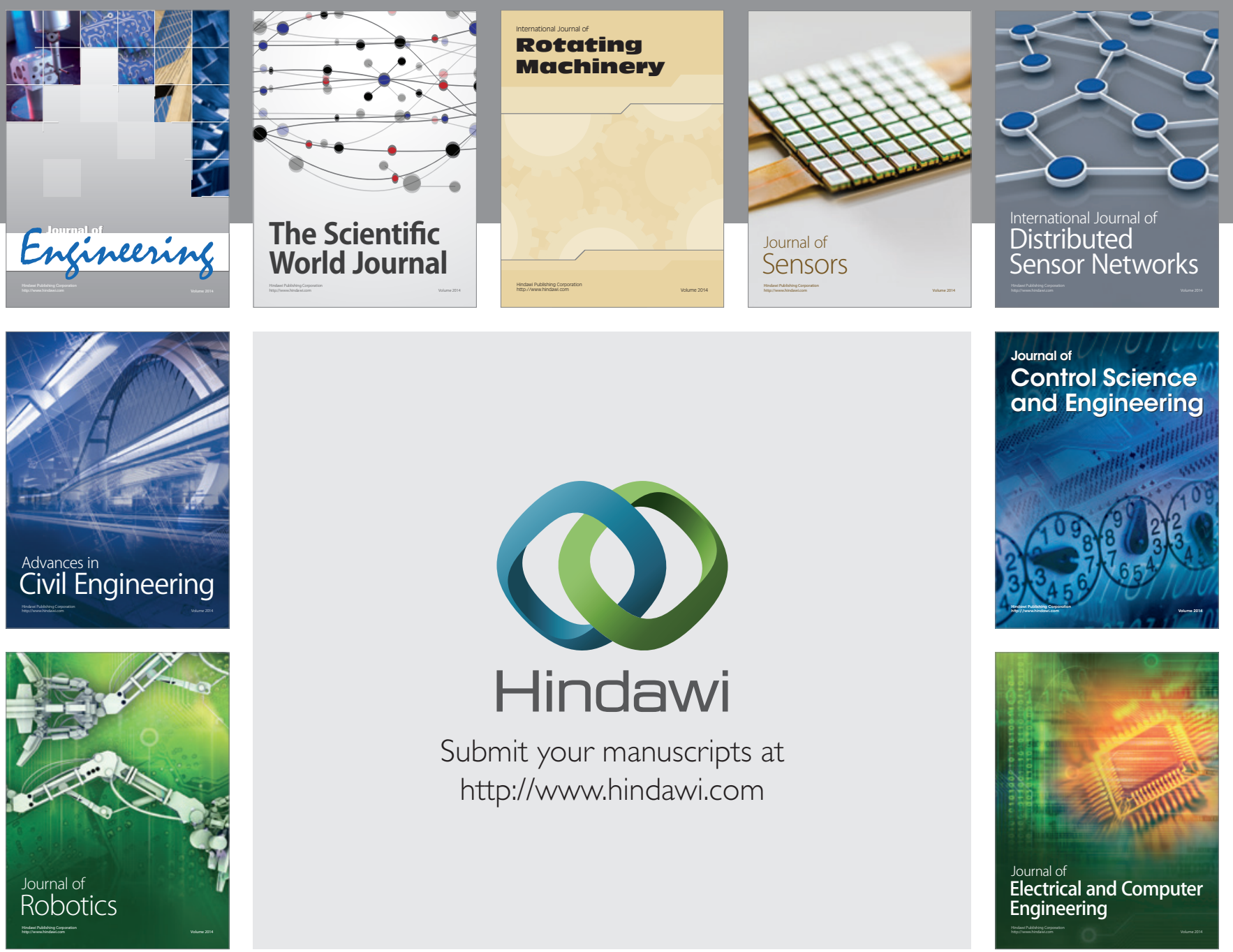

Submit your manuscripts at

http://www.hindawi.com
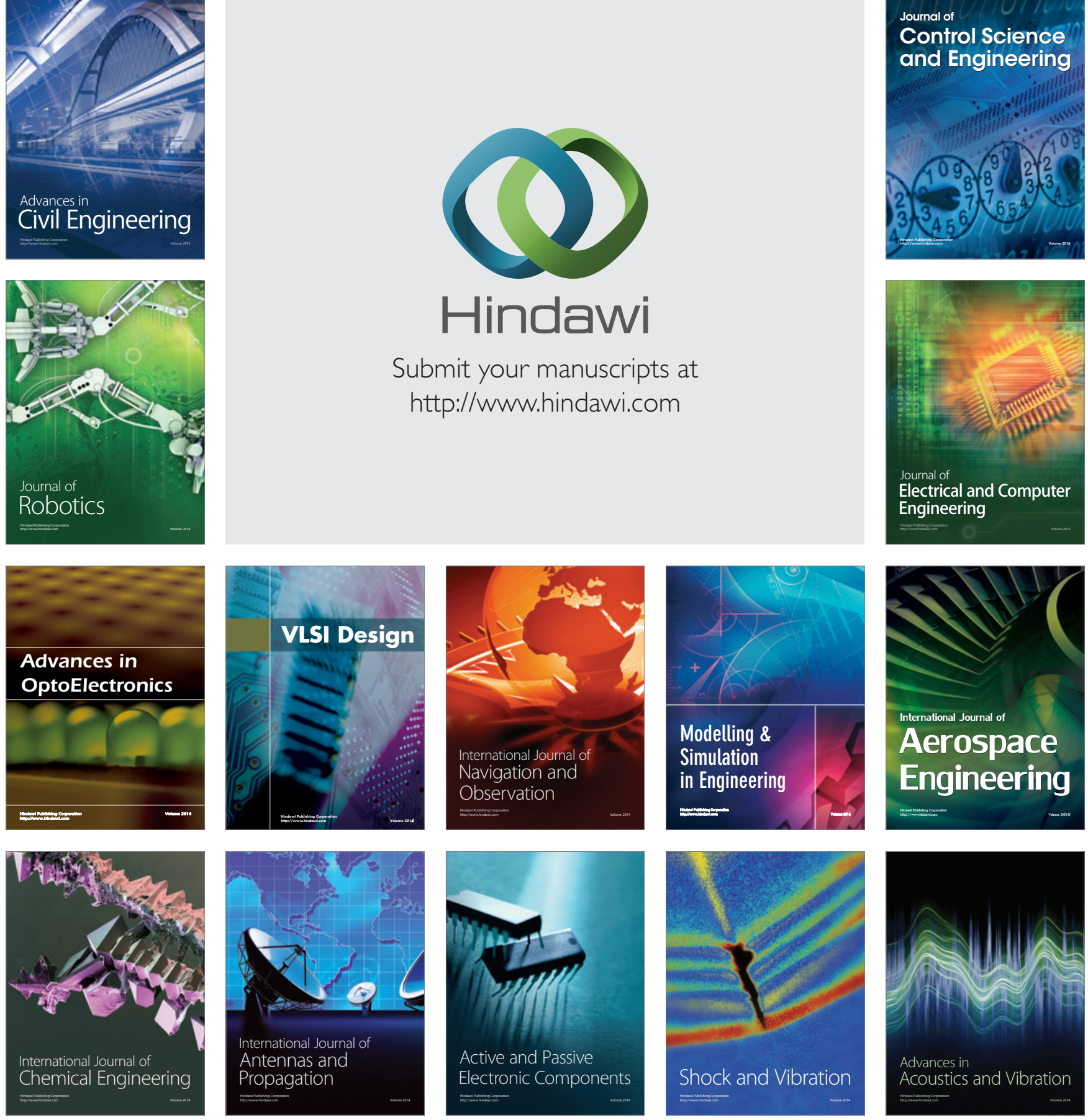